\title{
Cell death in granulomata: the role of apoptosis
}

\author{
I A CREE, S NURBHAI, G MILNE, J SWANSON BECK \\ From the Department of Pathology, Ninewells Hospital and Medical School, Dundee, Scotland
}

SUMMARY Unequivocal apoptoses were seen by light microscopy in examples of leprosy, sarcoidosis, tuberculosis, Crohn's disease and foreign body granulomata. A limited electron microscopic investigation showed typical apoptotic bodies in both sarcoid and leprosy granulomata. The number of apoptoses and mitoses in granulomata were counted and their densities calculated. The wide variation in the results between individual lesions may reflect differences in disease activity.

Current understanding of cell turnover in granulomata is based largely on studies of experimentally induced granulomata in animals by Dannenberg, Spector, and others. ${ }^{1}$ These experiments established that mononuclear phagocytes in granulomata have a finite life span and that this varies with the eliciting agent. The eventual fate of mononuclear cells in granulomata is not clear, although evidence from some studies suggests that cell death has a major role. $^{2}$ Cell necrosis is not readily apparent in noncaseating granulomata, however, and hence regression of differentiated mononuclear phagocytes to less mature forms with subsequent emigration from the lesion has been proposed as an alternative explanation. ${ }^{3}$

Another possible mechanism for the loss of mononuclear phagocytes from granulomata is apoptosis, a morphologically distinctive form of cell death which affects isolated cells in living tissue. ${ }^{4}$ Apoptosis occurs in a wide range of physiological and pathological circumstances, including involution of the adrenal cortex, ${ }^{5}$ secretory endometrium, ${ }^{6}$ tadpole tails, ${ }^{7}$ and basal cell carcinoma. ${ }^{8}$ Cells undergoing apoptosis show condensation and fragmentation into a number of membrane bound eosinophilic fragments which are then endocytosed by surrounding cells, even if these are not normally phagocytic. ${ }^{9}$ In contrast with true necrosis, cells undergoing apoptosis do not provoke an inflammatory response. As the process lasts a matter of hours, detection of even small numbers of apoptotic bodies within tissues indicates appreciable cell loss.

During a recent study of the histology of leprosy lesions, we observed apoptoses within both tuberculoid and lepromatous lesions. ${ }^{10}$ We now have extended these observations to include several other

Accepted for publication 28 May 1987 granulomatous conditions in man. In some of these it proved possible to count the apoptotic bodies and calculate their density within tissues to estimate cell loss by this mechanism. As the size of the granuloma reflects the balance of cell gain and cell loss mitoses were also counted to give an estimate of gain from this source. It was not possible to measure cellular immigration in fixed preparations.

\section{Material and methods}

Five granulomatous conditions were studied: leprosy tuberculosis, sarcoidosis, Crohn's disease, and foreign body granuloma. Biopsy specimens from the edge of leprosy lesions were obtained using a $4 \mathrm{~mm}$ sterile disposable skin punch (Stiefel Laboratories, Slough, England) from 29 untreated and seven treated Bangladeshi patients with leprosy. Informed consent was obtained verbally in all cases and histopathology reports were sent back to the relevant medical officers. After transportation to Britain in $4 \%$ buffered formaldehyde the biopsy specimens were bisected, embedded in paraffin wax, cut at $5 \mu \mathrm{m}$, and stained with haematoxylin and eosin.

Similarly processed sections of the other conditions obtained from the diagnostic histopathology files were stored at Ninewells Hospital. These were identified using the SNOP classification from biopsy specimens received over 18 months (July 1984 to December 1985). Cases were included in this study provided that: there was no doubt about the diagnosis; necrosis was absent; and well formed granulomata were present (table 1). A proportion of the cases examined were unsuitable for counting of apoptoses due to the presence of polymorphonuclear leucocyte debris, which it can sometimes be difficult to distinguish from apoptosis. Polymorphonuclear leucocyte infiltration was particularly prominent in the 
Table 1 No of cases and diagnosis

\begin{tabular}{lccc}
\hline Diagnosis & Total No examined & No counted & Granuloma area $\left(>0 \cdot 3\right.$ mm $\left.{ }^{2}\right)$ \\
\hline Foreign body granuloma & 13 & 13 & 13 \\
Leprosy & 56 & 56 & 36 \\
Sarcoidosis & 20 & 11 & 11 \\
Tuberculosis & 11 & 4 & 4 \\
Crohn's disease & 25 & 0 & 0 \\
Total & 127 & 86 & 64 \\
\hline
\end{tabular}

examples of Crohn's disease which were examined and none was suitable for quantitation of apoptoses.

\section{LIGHT MICROSCOPY}

Granulomata were identified by scanning the section at low power (at a magnification of 40). In some cases with large granulomata the areas for counting were delineated by marking the coverslip with a black felttip pen; in others the whole section or granuloma was examined. Apoptotic and mitotic bodies were counted by scanning the selected area at a magnification of 400 using a 25 square eyepiece grid (Leitz) to ensure that non-overlapping fields were examined. Structures were identified as apoptotic bodies if they satisfied three of the following four criteria: (i) ovoid or spherical shaped body; (ii) eosinophilia; (iii) separation from neighbouring cells; (iv) condensation or fragmentation, or both of nuclear material.

The area of the section occupied by granuloma was determined using an Imagan planimeter (Graphic Information Systems, Blairgowrie, Scotland) as previously described. ${ }^{11}$ Statistical analysis was performed using Statgraphics (STSC, California, USA) on an IBM PC-AT microcomputer. Differences in apoptotic and mitotic density between the conditions studied were examined using the Kruskal-Wallis test for one way analysis of variance by ranks.

\section{ELECTRON MICROSCOPY}

Material for electron microscopy was obtained from one case of sarcoidosis of the skin and from five cases of leprosy, all of which were classified as borderline tuberculoid or borderline lepromatous on the RidleyJopling scale. ${ }^{12}$ Large granulomata were identified on the cut surface of the fixed biopsy specimen using a stereoscopic microscope and dissected out. After fur-

Table 2 No of sections examined which contained apoptoses and mitoses

\begin{tabular}{llcl}
\hline & $\begin{array}{l}\text { Cases } \\
\text { with } \\
\text { apoptosis }\end{array}$ & $\begin{array}{l}\text { Cases } \\
\text { with } \\
\text { mitosis }\end{array}$ & Total \\
\hline Diagnosis & 5 & 5 & 13 \\
Foreign body granuloma & 33 & 19 & 56 \\
Leprosy & 14 & 9 & 20 \\
Sarcoidosis & 9 & 3 & 11 \\
Tuberculosis & 13 & 15 & 25 \\
Crohn's disease & & & \\
\hline
\end{tabular}

Table 3 No of cases with apoptoses and mitoses in sections with granuloma size of $>0.3 \mathrm{~mm}^{2}$

\begin{tabular}{lccl}
\hline Diagnosis & $\begin{array}{l}\text { Apoptosis } \\
\text { present }\end{array}$ & $\begin{array}{c}\text { Mitosis } \\
\text { present }\end{array}$ & $\begin{array}{l}\text { Total No } \\
\text { counted }\end{array}$ \\
\hline Foreign body granuloma & 5 & 5 & 13 \\
Leprosy & 27 & 19 & 36 \\
Sarcoidosis & 11 & 9 & 11 \\
Tuberculosis & 4 & 3 & 4 \\
Total & 47 & 36 & 64 \\
\hline
\end{tabular}

ther fixation in osmium tetroxide the blocks were embedded in araldite, ultrathin sections were cut, and then stained with uranyl acetate and lead citrate. The sections were viewed using a JEOL 100CX transmission electron microscope.

\section{Results}

Unequivocal apoptoses were seen in all of the types of granuloma studied, including Crohn's disease. Examples of the histological appearance of these are shown in fig 1. Although prolonged searching was necessary, the electron micrographs show typical apoptotic bodies at various stages of progression (fig 2), lying among epithelioid cells in one case of sarcoidosis of the skin and one case of borderline lepromatous leprosy.

Most of the apoptoses were found in areas consisting mainly of epithelioid cells in all of the granulomata studied, with the exception of lepromatous leprosy where they were scattered among the histiocytes. There was no microanatomical association between apoptoses and mitoses, which were commoner at the edge of the granulomata. Table 2 shows the number of cases with apoptoses and mitoses. Foreign body granulomata (FBG) were least likely to contain apoptoses, followed in order of increasing frequency by Crohn's disease, leprosy, sarcoidosis, and tuberculosis. Mitoses were least common in tuberculosis and commonest in Crohn's disease. Similar numbers of foreign body granuloma, leprosy, and sarcoidosis biopsy specimens contained mitoses, but these figures take no account of the area of the granuloma examined, which has to be of a certain size before rare cellular events are likely to be observed.

Measurement of the density of apoptosis in those 


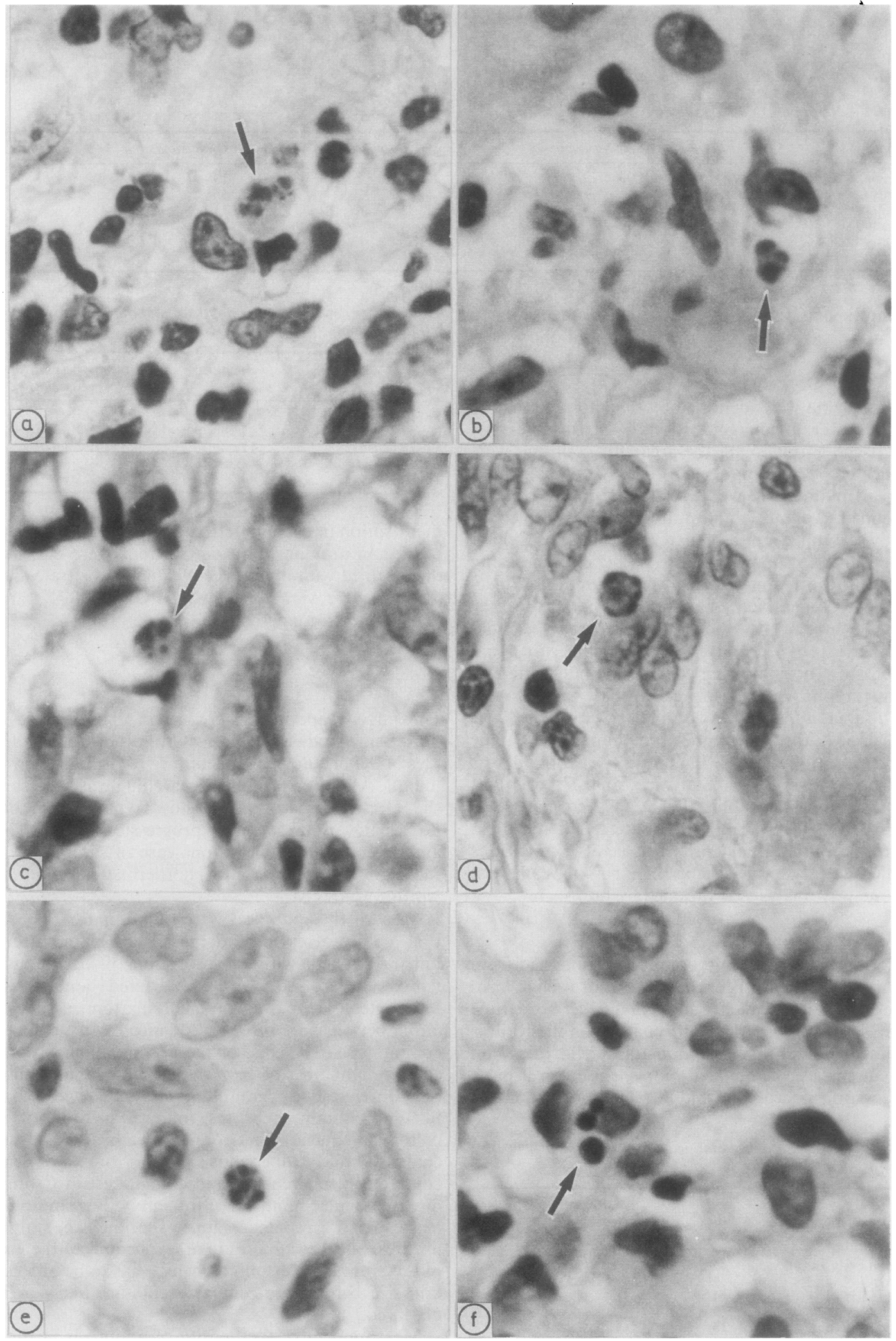

Fig 1 Examples of apoptoses (arrowed) in paraffin sections of human granulomata (a) foreign body granuloma; (b) sarcoidosis; (c) tuberculosis; (d) Crohn's disease; (e) tuberculoid leprosy; $(f)$ lepromatous leprosy. (Haematoxylin and eosin.) 
cases with granulomata of $0.3 \mathrm{~mm}^{2}$ area or greater (table 3, fig 3) confirm that even those foreign body granulomata with apoptoses have a lower apoptotic density than the other types of specimen examined. In all of the pathological specimens studied the density of apoptosis was much higher than mitosis, suggesting that apoptosis may be more common than mitosis in granulomata in man.
There were considerable differences between different patients with the same disease, particularly in leprosy. When the results from the leprosy biopsy specimens were examined against the clinicopathological classification of the patient on the Ridley-Jopling scale, ${ }^{12}$ certain patients in the borderline tuberculoid (BT), borderline lepromatous (BL), and lepromatous group showed high densities of apo-

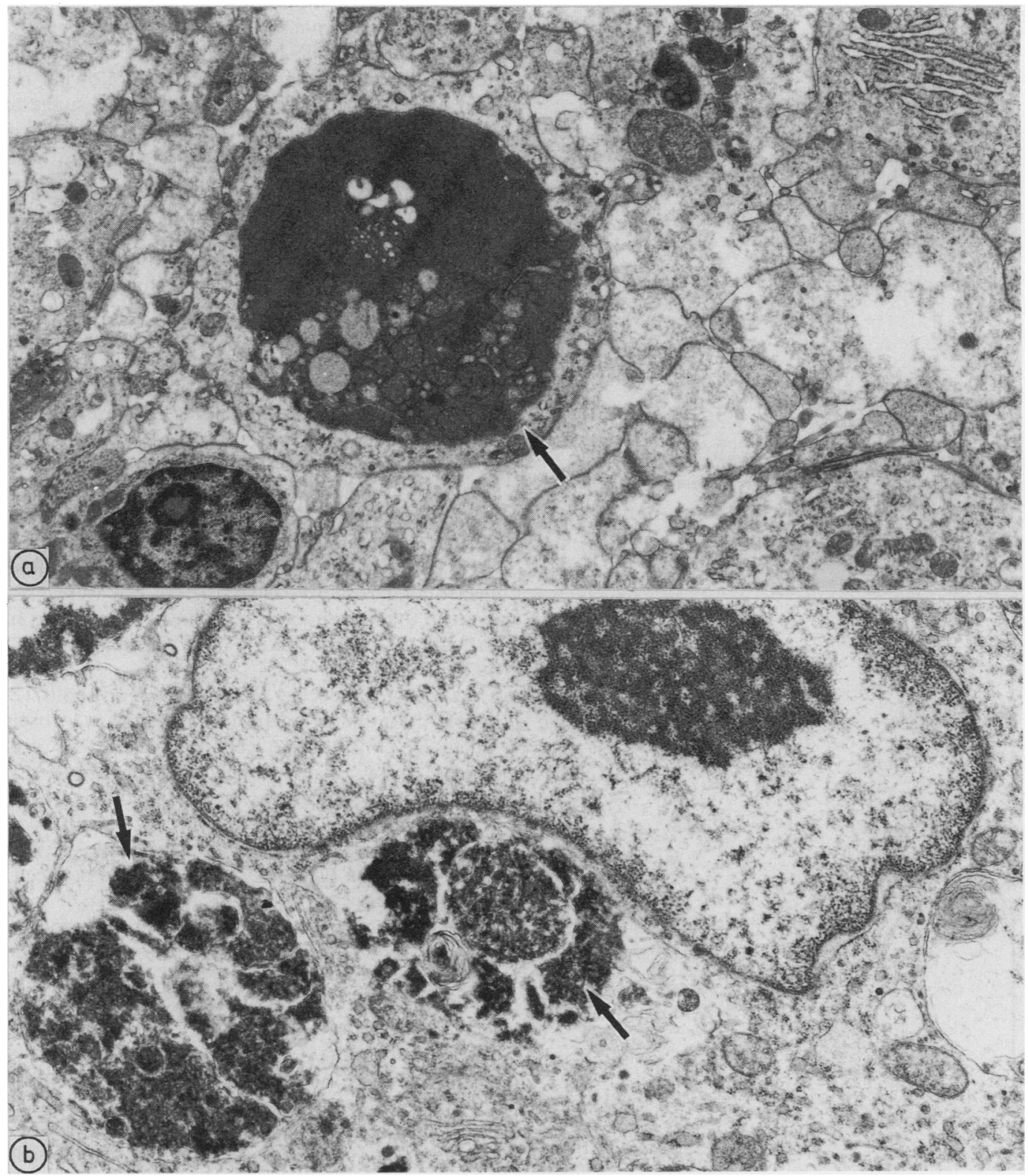

Fig 2 Electron micrographs of apoptotic bodies in (a) sarcoidosis and (b) borderline lepromatous leprosy. 

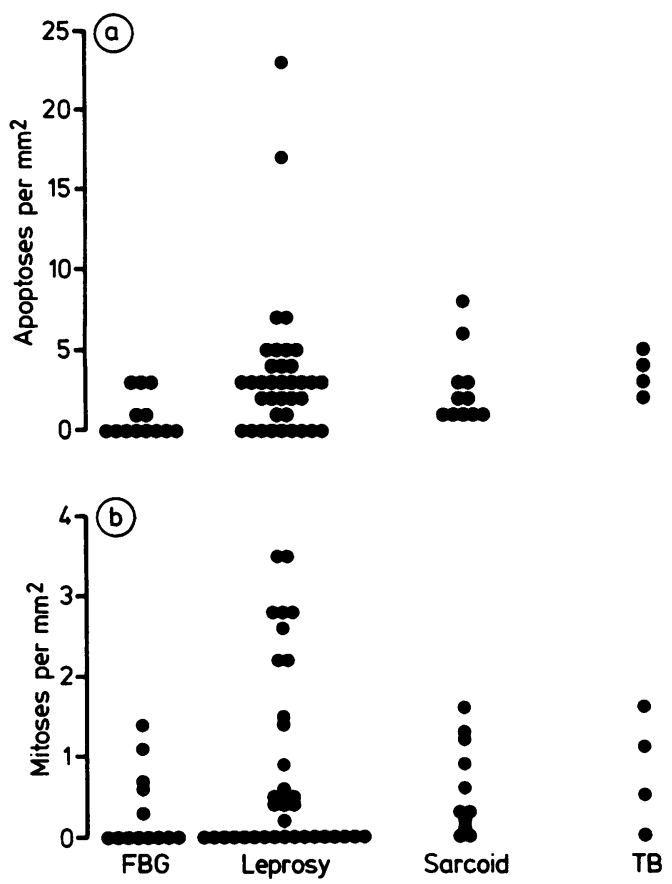

Fig 3 Density of apoptoses ( $a$ ) and mitoses (b) in each type of granuloma studied. Analysis of variance shows (a) apoptosis $p=0.01$; (b) mitosis $p=0.41$.
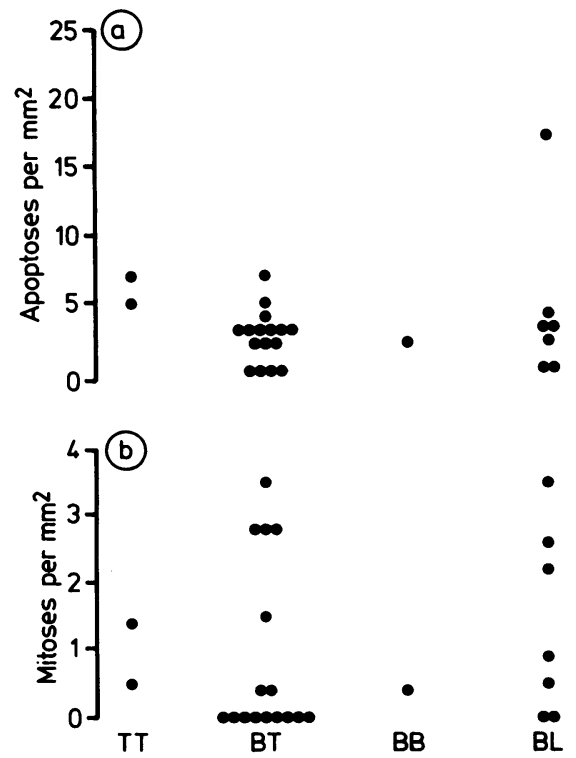

Fig 4 Density of apoptoses (a) and mitoses (b) against Ridley-Jopling classification in leprosy granulomata. ptosis and mitosis. The numbers of patients in each classification are too small for reliable conclusions to be drawn and further studies will be necessary to establish the clinical importance of a high apoptotic rate, although its presence is likely to indicate that such patients have a higher rate of cell turnover.

\section{Discussion}

The life span of mononuclear phagocytes in granulomata varies from a few days to several weeks. ${ }^{13-15}$ The fate of these cells has been in some doubt, but cell death, cell division, and emigration following reversion to less mature forms have all been suggested. ${ }^{1}$ Studies of experimental granulomata show that mononuclear cells do not divide repeatedly after they have entered the granuloma. ${ }^{2}$ Both emigration of cells from lesions ${ }^{16}$ and reversion to less mature forms have been shown to occur, ${ }^{3}$ but most authors consider that death of constituent cells in situ accounts for most of the cell loss that occurs during granuloma regression. ${ }^{1-3}$ Epithelioid cell death by necrosis is seen in tuberculosis at the edge of caseous areas, but in leprosy and sarcoidosis caseation is a rare occurrence and it could not account for the regression of the granulomata that commonly occurs with medical treatment. Apoptosis was seen in all of the granulomatous conditions which we studied and apoptotic bodies could be counted in the granu 8 lomata using the light microscope. As apoptosis affects individual cells which may be widely separated, apoptotic bodies can be difficult to find by? electron microscopy. Nevertheless, we were able to confirm their presence in both biopsy specimens from patients with sarcoidosis and leprosy using this method.

As apoptosis occurs over a period of about 12-18 hours, the number of apoptotic bodies we observed indicated considerable cell loss from the granulomata. ${ }^{17}$ This is in keeping with the degree of cell loss found in previous kinetic studies of experimentally induced granulomata. ${ }^{1}$ The occurrence of both apoptosis and caseation in tuberculosis is interesting, although there may be no relation between the two processes.

In comparison with the numbers of apoptoses present, only small numbers of mitoses were seen in each type of granuloma studied. There is considerable variation of mitotic density between individuals, as there is in apoptotic activity. The duration of mitosis is shorter than that of apoptosis, but our results suggest that many more cells were being lost as a result of apoptosis than were being gained by mitosis. This is consistent with data obtained from experimental granulomata which suggest that cell influx is more important in maintaining the size of the granuloma. ${ }^{11418}$ 
By studying the distribution and kinetics of labelled mononuclear cells in experimental granulomata, elicited by a variety of stimuli, Spector et al divided granulomata into high and low turnover types. ${ }^{131518}$ Low turnover granulomata form in response to carrageenan and other inert particles, whereas high turnover granulomata form in response to mycobacteria, such as BCG. Histologically, epithelioid cells and giant cells are rare in low turnover lesions but common in high turnover lesions. On the basis of this correlation it has been suggested that sarcoidosis is a high turnover granuloma. ${ }^{15}$ Our results show that apoptotic and mitotic activity vary between the various types of granuloma studied, as predicted by previous studies of experimental granulomata. Foreign body granulomata, which are often formed in response to inert materials, showed the lowest density of apoptoses and mitoses in this study. Tuberculosis and leprosy showed much higher rates of apoptosis and mitosis, observations which are predictable from their histology as well as their mycobacterial causation. The aetiologies of sarcoidosis and Crohn's disease are still a matter of controversy. Our results confirm previous suggestions that sarcoidosis is a high turnover granuloma, while the position of Crohn's disease is less clear. Human granulomata seem to exhibit a spectrum of cell turnover and may not fit neatly into high or low turnover categories. The place of individual disorders in this spectrum may correlate with the immunogenicity of the eliciting stimulus, but host factors must also be important, as shown by the variation in apoptotic and mitotic density between individuals with a particular disease (fig 3). The reasons for these differences are not clear from this study, but the possibility that they might be related to disease activity is of particular interest in leprosy in which certain patients have a propensity for the development of damaging immunologically mediated reactions, while others show no such tendency.

The balance between cell gain, resulting mainly from the influx of mononuclear cells, and cell loss are major determinants of the size, rate of expansion, and rate of regression of granulomata. Our results suggest that apoptosis plays a major part in the regression of granulomata in man. The factors which influence apoptotic activity and cell influx are likely to be important in determining whether a particular granulomatous lesion progresses or regresses during the development of the disease and whether it responds favourably to medical intervention.

We thank Drs D Hopwood, I H Cochrane, T Ali and Mr S Halda for their assistance. We are grateful to Mr G Coghill for technical assistance and to $\mathrm{Mr} \mathbf{R}$ Fawkes for preparation of the photographs. The work in Bangladesh was funded by the award of the
Becton Dickinson travelling scholarship to IAC by the Royal College of Pathologists. The laboratory work was funded by grants from LEPRA and James Finlay plc.

\section{References}

1 Adams DO. The granulomatous inflammatory response. A review. Am J Pathol 1976;84:161-83.

2 Dannenberg AM, Ando M, Shima K. Macrophage accumulation, division, maturation and digestive and microbiocidal capacities in tuberculous lesions. III. The turnover of macrophages and its relation to their activation and antimicrobial immunity and in primary BCG lesions and those of reinfection. J Immunol 1972;109:1 109-21.

3 Adams DO. The structure of mononuclear phagocytes differentiation in vivo. II: The effect of Mycobacterium tuberculosis. Am J Pathol 1975;80:101-16.

4 Kerr JFR, Bishop CJ, Searle J. Apoptosis. Recent Adv Histopathol 1984;12:1-15.

5 Wyllie AH, Kerr JFR, Macaskill IAM, Currie AR. Adrenocortical cell deletion: the role of ACTH. J Pathol 1973;111:85-94.

6 Hopwood D, Levison DA. Atrophy and apoptosis in the cyclical human endometrium. J Pathol 1976;1 19:159-66.

7 Kerr JFR, Harmon B, Searle J. An electron microscope study of cell deletion in the anuran tadpole tail during spontaneous metamorphosis with special reference to apoptosis of striated muscle fibres. J Cell Sci 1974;14:571-85.

8 Kerr JFR, Searle J. A suggested explanation for the paradoxically slow growth rate of basal cell carcinomas that contain numerous mitotic figures. J Pathol 1972;107:41-4.

9 Weedon D, Searle J, Kerr JFR. Apoptosis. Its nature and implications for dermatopathology. Am J Dermatopathol 1979;1:133-44.

10 Cree IA, Gardiner CA, Beck JS. Studies of cell death (apoptosis) and cell division in leprosy granulomata. International Journal of Leprosy 1986;54:607-13.

11 Cree IA, McDougall AC, Coghill G, Beck JS. Quantitation of the granuloma fraction in leprosy skin biopsies by planimetry. International Journal of Leprosy 1985;53:582-6.

12 Ridley DS, Jopling WH. Classification of leprosy according to immunity: a five group system. International Journal of Leprosy 1966;34:255-73.

13 Ryan GB, Spector WG. Natural selection of long-lived macrophages in experimental granulomata. J Pathol 1969;99:139-51.

14 Ando M, Dannenberg AM Jnr, Shima K. Macrophage accumulation, division, maturation and digestive and microbiocidal capacities in tuberculous lesions. II. Rate at which mononuclear cells enter and divide in primary BCG lesions and those of reinfection. J Immunol 1972;109:8-19.

15 Spector WG. Immunologic components of granuloma formation. Epithelioid cells, giant cells and sarcoidosis. Ann N Y Acad Sci 1976;278:3-6.

16 Smith JB, McIntosh GH, Morris B. The migration of cells through chronically inflamed tissues. J Pathol 1970;100:21-9.

17 Wyllie AH, Kerr JFR, Currie AR. Cell death: the significance of apoptosis. Int Rev Cytol 1980;68:251-306.

18 Papadimitriou JM, Spector WG. The ultrastructure of high- and low-turnover inflammatory granulomata. J Pathol 1972;106:37-43.

Requests for reprints to: Dr IA Cree, Department of Pathology, Ninewells Hospital and Medical School, PO Box 120, Dundee DDI 9SY, Scotland. 